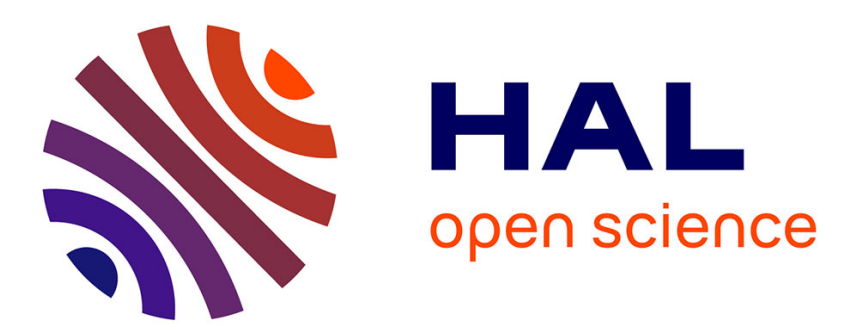

\title{
„Knowledge of HIV serostatus and risk behaviour among injecting drug users in Estonia“"
}

Katri Abel-Ollo, Anneli Uusküla

\section{To cite this version:}

Katri Abel-Ollo, Anneli Uusküla. „Knowledge of HIV serostatus and risk behaviour among injecting drug users in Estonia“. AIDS Care, 2009, 21 (07), pp.851-857. 10.1080/09540120802657522 . hal00545374

\section{HAL Id: hal-00545374 https://hal.science/hal-00545374}

Submitted on 10 Dec 2010

HAL is a multi-disciplinary open access archive for the deposit and dissemination of scientific research documents, whether they are published or not. The documents may come from teaching and research institutions in France or abroad, or from public or private research centers.
L'archive ouverte pluridisciplinaire HAL, est destinée au dépôt et à la diffusion de documents scientifiques de niveau recherche, publiés ou non, émanant des établissements d'enseignement et de recherche français ou étrangers, des laboratoires publics ou privés. 

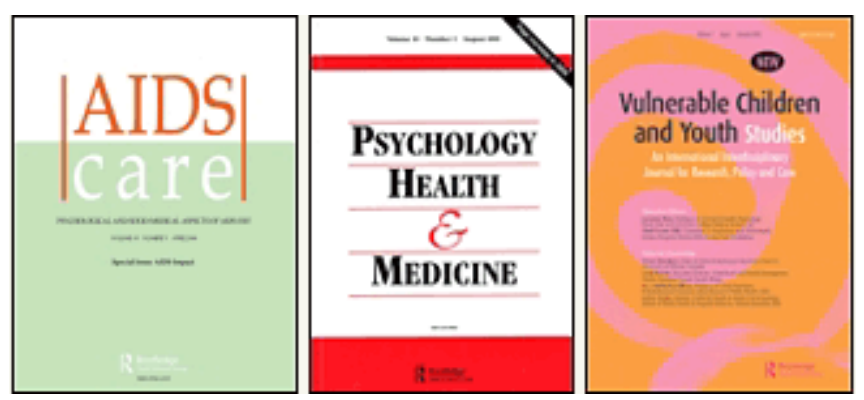

\section{„Knowledge of HIV serostatus and risk behaviour among injecting drug users in Estonia"}

\begin{tabular}{|r|l|}
\hline Journal: & $\begin{array}{l}\text { AIDS Care - Psychology, Health \& Medicine - Vulnerable Children } \\
\text { and Youth Studies }\end{array}$ \\
\hline Manuscript ID: & AC-2008-08-0356.R1 \\
\hline Journal Selection: & AIDS Care \\
\hline Keywords: & $\begin{array}{l}\text { Injecting drug use, HIV, knowledge of HIV serostatus, risk } \\
\text { behaviour, voluntary counselling and testing }\end{array}$ \\
\hline
\end{tabular}

\section{(1) ScholaroNE" \\ Manuscript Central}




\section{RESEARCH ARTICLE}

Knowledge of HIV Serostatus and Risk Behaviour among Injecting Drug Users in Estonia 


\begin{abstract}
We used the findings from two, cross-sectional studies of HIV serostatus and risk behaviours to assess the effects of knowledge of HIV serostatus and risk behaviours (relating to sex and injection drug use) among injecting drug users (IDUs). Respondent-driven sampling was used simultaneously at two sites in Estonia (the capital Tallinn, and the second- largest city of IdaVirumaa County, Kohtla-Järve). The research tool was an interviewer-administered survey. Biological samples were collected for HIV testing. Participants were categorized into three groups based on HIV testing results and self report on HIV serostatus: HIV-negative ( $\mathrm{n}=133$ ); HIVpositive unaware of their serostatus ( $n=75)$; and HIV-positive aware of their serostatus $(n=168)$. In total, $65 \%$ of the participants tested positive for HIV. Of those $69 \%$ were aware of their positive serostatus. HIV-positive IDUs aware of their serostatus exhibited more risk behaviours than their HIV-positive counterparts unaware of their serostatus or HIV-negative IDUs. Effective prevention of HIV among IDUs should therefore include programmes to reduce high risk sexual and drug use behaviours at the public health scale and enhanced prevention efforts focusing on HIV-infected individuals.
\end{abstract}

KEYWORDS: Injecting drug use, HIV, knowledge of HIV serostatus, risk behaviour, voluntary counselling and testing. 


\section{Introduction}

In the last decade, Estonia has faced the highest increase in the incidence of HIV infection in Europe (rising from 7.2 per million in 1998 to 504 per million in 2005). The HIV epidemic in Estonia, as in other Eastern European countries, is mainly driven by injection drug use (EuroHIV, 2007). The estimated prevalence of injecting drug use in Estonia is 2.4\% among 15-44-year olds (Uusküla et al., 2007). Local studies performed in the last 2 years have shown prevalences of up to 90\% (Platt et al., 2006; Wilson, Sharma, Zilmer, Kalikova, \& Uusküla, 2007; Uusküla, Heimer, Dehovitz, Fischer, \& McNutt, 2006; Uusküla, McNutt, Dehovitz, Fischer, \& Heimer, 2007;) and a high incidence of HIV among injecting drug users (IDUs) (>20/100 person-years at risk) (Uusküla et al., 2008).

Research over the last decade shows that knowledge of HIV serostatus can affect risk behaviours and that protective behaviours tend to increase following notification of positive HIV status (Casadonte, Des Jarlais, Freiedman, \& Rotrosen, 1990; Deren, Beardsley, Tortu, \& Goldstein, 1998; Desenclos, Papaevangelou, \& Ancelle-Park, 1993; Rhodes, Donoghoe, Hunter, \& Stimson, 1993; Wolitski, MacGowan, Higgins, \& Jorgensen, 1997). At the same time, however, a significant number of HIV-infected individuals continue to engage in risky behaviour (Avants, Warburton, Hawkins, \& Margolin, 2000; McCusker et al., 1994; Singh et al., 1993; van Deb Hoek, van Haastrecht, \& Coutinho, 1989).

Previous studies have examined the prevalence of HIV and its association with risk behaviour within the samples as a whole (Platt et al., 2006). In this report, we explore the relationships between knowledge of HIV serostatus and risk behaviour for HIV (both injecting and sexual) among IDUs in two Estonian cities with a high prevalence of HIV.

\section{Methods}

\section{Study design}

In 2005, two cross-sectional studies designed to assess the HIV prevalence and risk behaviours among current IDUs were conducted using respondent-driven sampling (RDS) (Heckathorn, Semaan, Broadhead, \& Hughes, 2002) simultaneously in two sites in 
Estonia (the capital city Tallinn, and the second largest city of Ida-Virumaa County, Kohtla-Järve). In both studies current IDUs were recruited for a paper-based, intervieweradministered risk behaviour survey covering demographics, sexual behaviour and drug use history, together with biological sample collection for HIV testing.

Eligibility criteria included reporting injecting drugs within the past 90 days, age of 18 years or older and consent to provide a biological sample (dry blood spot) for HIV testing. To ensure the IDU status, the skin (arms and legs) of the study subjects was checked for injection marks and/or they were asked to describe the process of preparing drugs for injection.

Behavioural data was collected using a structured questionnaire developed from a previous questionnaire, which had been used extensively in a variety of multicentre studies in resource-constrained and developed countries including the Russian Federation (Rhodes et al., 2002). The questionnaire included questions about previous HIV testing and reported HIV antibody status. Knowledge of HIV serostatus was recorded by comparing the self-report of the study subjects of earlier HIV testing with the result obtained from the blood test.

\section{HIV antibody testing}

Dried blood spot specimens were collected using single-use disposable lancets and neonatal Guthrie cards to detect antibodies to HIV (anti-HIV). Specimens were screened using anti-HIV GACELISA, and reactive specimens were confirmed using anti-HIV GACPAT immunoassay (Conell, Parry, Mortimer, \& Duncan, 1993; Parry et al., 1995). Subsequent confirmatory testing was conducted on discordant results using the HIV Blot 2.2 Western Blot assay (AbbotMurex). Testing was undertaken at the UK Health Protection Agency. At the end of study, participants were offered referrals for voluntary HIV counselling and testing.

\section{Statistical analysis}

For the purposes of the current study, IDUs were categorised into three groups based on self report and HIV testing results: HIV-negative, HIV-positive unaware of their seropositive status, and HIV-positive aware of their serostatus. 
The following indicators for injecting drug use and sexual risk behaviours were used: (i) receptive sharing of syringes, needles; (ii) sharing water; (iii) having unprotected vaginal / anal intercourse within the last 4 weeks or last 12 months; (iv) receptive sharing of needles with a sexual partner; (v) having an IDU as a sexual partner; (vi) having 2 or more sexual partners within the last 12 months. The threshold for the number of sexual partners was set after consideration of the long time period of the study (12 months) and the research target group.

Sexual and drug use risk behaviours were assessed for their relationship with HIV serostatus/knowledge of HIV status through logistic regression models and bivariate measures of association. HIV-infected IDUs aware and unaware of their serostatus were compared to the uninfected IDUs, using the latter as a reference group. In addition, a comparison within the HIV-positive group was made using the HIV-positive individuals aware of their serostatus as a reference group. Adjusted odds ratios (AOR) and 95\% confidence intervals (CIs) are presented. We adjusted for the following variables: site; gender; age; ethnicity; frequency of injections (1-3 times a day); reported prison experience; age when participant started injecting drugs.

STATA software was used to calculate the statistical significance: ANOVA for continuous variables and $\chi^{z}$ test or Fisher's exact test for the categorical variables. Logistic regression was used to calculate AORs. RDS analysis Tool v. 5.0.1 was used to weight the sample to control for differences in network size and homophily to provide population-based estimates of study population characteristics (Volz, Wejnert, Degani \& Heckathorn, 2007).

The study was approved by the Ethics Committee on Human Research at the University of Tartu, Estonia, and Riverside Research Ethics Committee, London, UK.

\section{Results}

We recruited 450 IDUs to the study: 350 in Tallinn and 100 in Kohtla-Järve. Of these, 376 provided data for analysis (Table 1). Respondents who did not report HIV testing before the study $(n=52)$ or did not report any test result $(n=16)$ were excluded from the analysis. An HIV antibody test result was missing for one participant. Five IDUs who reported that they were HIV-positive, but who tested HIV-negative at the time of the study were also excluded from the analysis. The study participants excluded from the analysis $(\mathrm{N}=74)$ did not differ from those included in terms of age, gender, ethnicity, site, 
HIV serostatus, daily injecting, frequency of injecting, age at initiation, receptive sharing of needles/syringes with IDUs, HIV-positive sexual partner and unprotected sexual intercourse. The majority of participants were men (84\%), non-Estonians (89\%), and used fentanyl (or "china white", synthetic opiate) (61\%) as their main drug.

\section{Insert Table 1}

Of the 376 respondents analysed, $35.4 \%(\mathrm{~N}=133)$ tested negative for HIV antibodies, while $64.6 \%(\mathrm{~N}=243)$ were HIV-positive. Of those testing positive for HIV antibodies, $69.1 \%(168 / 243)$ reported having a positive HIV test in the past (and were therefore aware of their seropositive status) and 30.9\% (75/243) reported being HIV-negative when last tested (i.e., were unaware of their seropositive status).

Those who tested HIV-negative were less likely to inject daily (36.8\% vs. $58.3 \%$ for HIV-positive aware and 52.0\% for HIV-positive unaware, $\mathrm{p}<0.001$ ), were older when they started to inject drugs (18.4 years vs. 16.7 for HIV-positive aware and 16.1 for HIVpositive unaware, $\mathrm{p}=0.01$ ). The average age at interview was 25.3 years for HIV-negative, 24.3 years for HIV-positive aware and 23.0 years for HIV-positive unaware. The HIVpositive IDUs aware of their serostatus were more likely to be in contact with harm reduction services (90.5\% vs. HIV-negative $76.7 \%$ and HIV-positive unaware $73.3 \%$, p< 0.001). There were no differences in measures of risky sexual behaviour (having unprotected intercourse or having multiple partners) within these three groups of IDUs (Table 2).

\section{Insert Table 2}

We assessed both sexual and drug-use risk behaviours for HIV as a function of HIV serostatus and awareness. The first comparison was done among those infected with HIV (Table 3). Those who were HIV positive and aware of their serostatus had higher odds of receptive sharing of used syringes/needles and of sharing water with peers in the last four weeks (needles/syringes: AOR 2.19 [95\% CI 1.09-4.39], water: AOR 2.96 [1.40-6.24], with a sexual partner in the last year (AOR 5.09 [2.21-11.71]), or with HIV-positive individuals at any time (AOR 30.6 [9.65-97.26]). They were also four times more likely to have an IDU as a sexual partner (AOR 4.07 [2.02-8.20]). 
We also compared HIV-negative and HIV-positive respondents (Table 4). HIVpositive individuals aware of their serostatus were more likely to share injection equipment, or to have an IDU as a sexual partner (AOR 2.42 [1.31-4.47]). HIV-positive IDUs unaware of their serostatus did not differ from HIV-negative IDUs in their risk behaviours except for having twice the odds for unprotected intercourse in the last year (AOR $2.44[1.24-4.80])$.

\section{Insert Table 3}

Insert Table 4

Potential recruitment biases were explored using RDSAT to adjust for differences in network size and for homophily (respondent-driven sampling). We specifically looked at the proportions of individuals who were HIV-negative, HIV-positive unaware of their seropositive status, and HIV-positive aware of their serostatus in the sample population. The population estimates were generally similar to the values observed in the total population. All observed sample proportions fell within the $95 \%$ confidence intervals (CI) of the RDS adjusted population estimates: HIV-positive unaware 0.19 vs 0.22 [95\% CI 0.14-0.31]; HIV-positive aware 0.42 vs 0.33 [0.26-0.43]), and HIV-negative aware 0.34 vs 0.42 [CI 0.32.-0.51] for sample and estimated total population respectively.

\section{Discussion}

HIV prevention efforts to date have focused primarily on reducing the risk of infection among HIV-negative individuals, concentrating on those individuals who engage in "high risk" sexual and drug using activities. Considerably less attention has been given to prevention efforts targeting individuals already infected with HIV.

Our findings suggest that HIV-positive individuals who are aware of their serostatus may have a tendency to continue high risk activities. Based on the results of the current study, risk-taking seems to be more common among that group.

We found that HIV-positive IDUs aware of their serostatus exhibited the highest risk behaviours. HIV-positive IDUs aware of their serostatus reported higher injection risk behaviours (such as receptive sharing, sharing with a known HIV-positive person, sharing 
with a sexual partner) than their HIV-positive counterparts unaware of their HIV serostatus or than the HIV-negative IDUs.

As with any study, the limitations should be considered. The cross-sectional design does not allow us to establish a causal relationship or a direction of causality. In addition, there is the potential for information bias inherent to research on illicit drug use and sexual behaviour. There can be a tendency for individuals to avoid negative evaluations and to project a positive view of themselves by providing reports on their behaviour that are socially desirable. This response bias may interfere in the case of especially sensitive topics, such as drug use and sexual behaviour (Latkin, \& Vlahov, 1998). Moreover, the selective, constructive process of remembering makes self-reporting subject to memory biases (Hammersley, 1994). To diminish the potential biases of self-reporting, respondents obviously under the immediate influence of drugs were asked to return when sober. In addition, the respondents were anonymous, and unlinked interviews were held with trained interviewers in a familiar environment.

Our findings suggest that awareness of serostatus alone does not result in altered riskbehaviour profiles. A randomized controlled trial has shown that HIV testing without proper counselling has little effect on HIV risk behaviour and that knowledge of serostatus is only instrumental in changing risk behaviours when combined with intensive counselling (Kamb et al., 1998). There is also a concern that HIV testing without counselling could actually promote risky behaviour (Mertens, Smith, \& Van Praag, 1994; Van der Perre, 2000). Voluntary testing and counselling (VCT) is available in Estonia and most VCT services in Estonia are trained to give pre- and post-test counselling. However the quality of VCT service is unknown and no national guidelines exist to regulate or assess current VCT services.

Given the high levels of risk behaviour among HIV-positive IDUs aware of their serostatus, HIV testing should be followed by counselling in combination with other interventions directed at fostering long-term behavioural change (Crepaz et al., 2006; Rhodes, Singer, Bourgois, Friedman, \& Strathdee, 2005; Marks, Burris, \& Peterman, 1999). This is especially important in situations where a variety of social and environmental factors interplay to produce or sustain risk (Rhodes, \& Simic, 2005).

The findings of this study have significant policy implications, suggesting an urgent need for enhanced interventions targeting HIV-positive IDUs attending for clinical care or contacting harm reduction services via other routes. Interventions need to target both injection and sexual risk reduction and access to HIV treatment and treatment for 
substance abuse/addiction. Given the high sexual risk behaviour and HIV prevalence among our study subjects the population groups at the most imminent risk are the sexual partners of current IDUs. Implementation of prevention efforts targeting IDU sex partners is therefore of vital importance in changing the course of epidemic. For example, drugtreatment programs could intensify efforts to reach partners of their IDU clients by making use of extensive staff training in HIV issues, innovative outreach methods, and creative counselling strategies (CDC, 1991; Klevens, Fleming, Neal, \& Li, 2001; Iguchi, Donald, Kushner, \& Lidz, 2001).

\section{Acknowledgement}




\section{REFERENCES}

Avants, S.K., Warburton, L.A, Hawkins, K.A., \& Margolin, A. (2000). Continuation of high-risk behaviour by HIV-positive drug users: treatment implications. Journal of Substance Abuse Treatment, 19(1), 15-22.

Casadonte, P.P., Des Jarlais, D.C., Freiedman, S.R., \& Rotrosen, J.P. (1990).

Psychological and behavioral impact among intravenous drug users of learning HIV test results. The International Journal of the Addictions, 25(4), 409-426.

Centers for Disease Control. (1991). Drug use and sexual behaviors among sex partners of injecting-drug users--United States, 1988-1990. MMWR Morb Mortal Wkly Rep, 13(49), 855-60.

Conell, J.A., Parry, J.V., Mortimer, P.P., \& Duncan, J. (1993). Novel assay for the detection of immunoglobulin $\mathrm{G}$ anti-human immunodeficiency virus in untreated saliva and urine. Journal of Medical Virology, 41(2), 159-164.

Crepaz, N., Lyles, C.M., Wolitski, R.J., Passin, W.F., Rama, S.M., Herbst, J.H., et al. (2006). Do prevention interventions reduce HIV risk behaviours among people living with HIV? A meta-analytic review of controlled trials. AIDS, 20(2), 143-157.

Deren, S., Beardsley, M., Tortu, S., \& Goldstein, M.F. (1998). HIV serostatus and changes in risk behaviors among drug injectors and crack users. AIDS and Behavior, 2(2), 171-176.

Desenclos, J., Papaevangelou, G., \& Ancelle-Park, R. (1993). Knowledge of HIV serostatus and preventive behaviour among European injecting drug users. The European Community Study Group on HIV in Injecting Drug Users. AIDS, 7(10), 1371-1377.

EuroHIV. HIV/AIDS Surveillance in Europe. End-year report 2006.Retrieved June 25, 2008, from http://www.eurohiv.org/reports/report_75/pdf/report_eurohiv_75.pdf

Hammersley, R. (1994). A digest of memory phenomena for addiction research.

Addiction, 89(3), 283-293.

Heckathorn, D.D., Semaan, S., Broadhead, R.S., \& Hughes, J.J. (2002). Extensions of respondent-driven sampling: a new approach to the study of injecting drug users aged 18-25. AIDS and Behavior, 6(1), 55-67.

Iguchi, M.Y., Donald, A.B., Kushner, H., \& Lidz, V. (2001). Correlates of HIV risk among female sex partners of injecting drug users in a high-seroprevalence area. Eval Program Plann, 24, 175-185. 
Kamb, M.L., Fishbein, M., Douglas, J.M., Rhodes, F., Rogers, J., Bolan, G., et al. (1998). Efficacy of risk reduction counselling to prevent human immunodeficiency virus and sexually transmitted diseases. JAMA, 280(13), 1161-1168.

Klevens, R.M., Fleming, P.L., Neal, J.J., Li, J. (2001). Knowledge of partner risk and secondary transmission of HIV. Am J Prev Med, 20(4), 277-281.

Latkin, C.A., \& Vlahov, D. (1998). Socially desirable response tendency as a correlate of accuracy of self-reported HIV serostatus for HIV-positive drug users. Addiction, 93(8), 1191-1197.

Marks, G., Burris, S., \& Peterman, T.A. (1999). Reducing sexual transmission of HIV from those who know they are infected: the need for personal and collective responsibility. AIDS, 13(3), 297-306.

McCusker, J., Bigelow, C., Frost, R., Hindin, R., Vickers-Lahti, M., \& Zorn, M. (1994). The relationships of HIV status and HIV risky behavior with readiness for treatment. Drug and Alcohol Dependence, 34(2), 129-138.

Mertens, T.E., Smith, G.D., \& Van Praag, E. (1994). Home Testing for HIV. Lancet, 343(8908), 1293.

Parry, J.V., Connell, J.A., Reinbott, P., Garcia, A.B., Avillez, F., \& Mortimer, P.P. (1995). GACPAT HIV 1+2: A Simple inexpensive assay to screen for, and discriminate between, anti-HIV 1 and anti-HIV 2. Journal of Medical Virology, 45(1), 10-16.

Platt, L., Bobrova, N., Rhodes, T., Uusküla, A., Parry, J.V., Rüütel, K., et al. (2006). High HIV prevalence among injecting drug users in Estonia: implications for understanding the risk environment. AIDS, 20(16), 2120-2123.

Rhodes, T.J., Donoghoe, M.C., Hunter, G.M., \& Stimson, G.V. (1993). Continued risk behaviour among HIV-positive drug injectors in London. Implications for intervention. Addiction, 88(11), 1553-1560.

Rhodes, T., Lowndes, C., Judd, A., Mikhailova, L.A, Sarang, A., Rylkov, A., et al. (2002). Explosive spread and high prevalence of HIV among injecting drug users in Togliatti city, Russia: implications for HIV prevention. AIDS, 16(13), 25-31.

Rhodes, T., \& Simic, M. (2005). Transition and the HIV risk environment. BMJ, 331(7510), 220-223.

Rhodes, T., Singer, M., Bourgois, P., Friedman, S.R., \& Strathdee, S.A. (2005). The social structural production of HIV risk among injecting drug users. Social Science \& Medicine, 61(5), 1026-1044. 
Singh, B.K., Koman, J.J.3rd., Catan, V.M., Souply, K.L., Birkel, R.C., \& Golaszewski, T.J. (1993). Sexual risk behaviour among injection drug-using human immunodeficiency virus positive clients. The International Journal of the Addictions, 28(8), $735-747$.

Uusküla, A., Heimer, R., Dehovitz, J., Fischer, K., \& McNutt, L.A. (2006). Surveillance of HIV, Hepatitis B virus, and Hepatitis C virus in an Estonian injection drug-using population: sensitivity and specificity of testing syringes for public health surveillance. International Journal of Infectious Diseases, 193(3), 455-457.

Uusküla, A., Kals, M., Rajaleid, K., Abel, K., Talu, A., Rüütel, K., et al. (2008). Highprevalence and high-estimated incidence of HIV infection among new injecting drug users in Estonia: need for large scale prevention programs. Journal of Public Health (Oxford, England), 30(2), 119-125.

Uusküla, A., McNutt, L.A., Dehovitz, J., Fischer, K., \& Heimer, R. (2007). High prevalence of blood-borne virus infections and high-risk behaviour among injecting drug users in Tallinn, Estonia. International Journal of STD \& AIDS, 18(1), 41-46.

Uusküla, A., Rajaleid, K., Talu, A., Abel, K., Rüütel, K., \& Hay, G. (2007). Estimating injection drug use prevalence using state wide administrative data sources: Estonia, 2004. Addiction Research and Theory, 15(4), 411-424.

van Deb Hoek, J.A.R., van Haastrecht, H., \& Coutinho, R.A. (1989). Risk reduction among intravenous drug users in Amsterdam under the influence of AIDS. American Journal of Public Health, 79(10), 1355-1357.

Van der Perre, P. (2000). HIV voluntary counselling and testing in community health services [commentary]. Lancet, 356(9224), 86-87.

Volz, E., Wejnert, C., Degani, I., \& Heckathorn, D.D. (2007). Respondent-driven sampling analysis tool (RDSAT) Version 5.6. Ithaca, NY: Cornell University. Retrieved June 16, 2008, from http://www.respondentdrivensampling.org/

Wilson, T.E., Sharma, A., Zilmer, K., Kalikova, N., \& Uusküla, A. (2007). The HIV prevention needs of injecting drug users in Estonia. International journal of STD \& AIDS, 18(6), 389-391.

Wolitski, R.J., MacGowan, R.J., Higgins, D.L., \& Jorgensen, C. M. (1997). The effects of HIV counselling and testing and help-seeking behaviour. AIDS Education and Prevention, 9 (Suppl.3), 52-67. 


\section{TABLES}

Table 1 HIV serostatus of respondents according to self-report and antibody test result, injecting drug user survey 2005, Estonia

\begin{tabular}{lccccc}
\hline & & \multicolumn{2}{c}{ Self-reported HIV-serostatus } \\
HIV test result & Positive & Negative & Unknown & $\begin{array}{l}\text { Missing } \\
\text { cases }\end{array}$ & Total \\
\hline Positive & 168 & 75 & 12 & 24 & 279 \\
Negative & 5 & 133 & 4 & 28 & 170 \\
Total & 173 & 208 & 16 & 52 & 449 \\
\hline
\end{tabular}

*previously tested, with result unknown

***never previously tested 
Table 2 Main characteristics of respondents according to knowledge of their HIV serostatus, injecting drug user survey 2005, Estonia

\begin{tabular}{|c|c|c|c|c|}
\hline \multirow[b]{3}{*}{ Characteristic } & \multirow{2}{*}{$\begin{array}{l}\text { HIV- } \\
\text { negative } \\
\text { aware of } \\
\text { serostatus } \\
(n=133)\end{array}$} & \multicolumn{2}{|c|}{ HIV-positive } & \multirow[b]{3}{*}{ p-value } \\
\hline & & $\begin{array}{l}\text { aware of } \\
\text { serostatus } \\
(n=168)\end{array}$ & $\begin{array}{l}\text { unaware of } \\
\text { serostatus } \\
(n=75)\end{array}$ & \\
\hline & $\%$ & $\%$ & $\%$ & \\
\hline Gender (proportion of men) & 86.5 & 79.2 & 88.0 & 0.12 \\
\hline Ethnicity (non-Estonians) & 83.5 & 92.9 & 91.9 & 0.02 \\
\hline Injecting drug use & & & & \\
\hline Daily injectors & 36.8 & 58.3 & 52.0 & $<0.00$ \\
\hline $\begin{array}{l}\text { Frequency of injection (1-3 times } \\
\text { a day) }\end{array}$ & 82.0 & 72.6 & 82.4 & 0.09 \\
\hline Fentanyl as main drug used & 63.1 & 64.2 & 50.7 & 0.13 \\
\hline Environmental factors & & & & \\
\hline Ever in jail & 64.7 & 69.1 & 64.0 & 0.64 \\
\hline $\begin{array}{l}\text { Contact with harm-reduction } \\
\text { services } \\
\text { Sexual risk behaviour factors }\end{array}$ & 76.7 & 90.5 & 73.3 & $<0.00$ \\
\hline $\begin{array}{l}\text { Unprotected intercourse } \\
\text { (anal or vaginal), last } 4 \text { weeks }\end{array}$ & 51.9 & 51.3 & 43.6 & 0.56 \\
\hline $\begin{array}{l}\text { Having } 2 \text { or more sexual partners, } \\
\text { last } 12 \text { months }\end{array}$ & 61.7 & 60.7 & 48.0 & 0.12 \\
\hline $\begin{array}{l}\text { Unprotected intercourse (anal or } \\
\text { vaginal), last } 12 \text { months }\end{array}$ & 61.6 & 56.8 & 46.4 & 0.09 \\
\hline Injecting risk behaviour factors & & & & \\
\hline Sharing used syringes/needles, & & & & \\
\hline last 4 weeks & 24.9 & 36.1 & 21.6 & 0.02 \\
\hline Sharing water, last 4 weeks & 44.2 & 47.6 & 28.0 & 0.02 \\
\hline $\begin{array}{l}\text { Sharing injection equipment with } \\
\text { sex partner, last } 12 \text { months }\end{array}$ & 19.2 & 41.5 & 13.0 & $<0.00$ \\
\hline $\begin{array}{l}\text { Sharing with HIV-positive } \\
\text { person, lifetime }\end{array}$ & 18.6 & 66.9 & 7.41 & $<0.00$ \\
\hline
\end{tabular}


Table 3 Odds ratios of risk behaviours of HIV-positive IDUs according to knowledge of HIV serostatus, injecting drug user survey 2005, Estonia

Aware vs. unaware of HIV serostatus OR $(95 \% \mathrm{CI}) * *$

Risk behaviour, last 4 weeks

Sharing used syringes/needles

$2.19(1.09-4.39)$

Unprotected intercourse (anal or vaginal)

Sharing water

Risk behaviour, last 12 months

IDU as sexual partner

Sharing injection equipment with sex

partner

Having 2 or more sexual partners

Unprotected intercourse

Risk behaviour, lifetime

Sharing with HIV-positive person

$30.6(9.65-97.26)$

* adjusted for site, gender, age, ethnicity, frequency of injection, jailed in the past, age at IDU initiation ** ref group is HIV-positive aware of serostatus 
Table 4 Odds ratios of risk behaviours of IDUs according to knowledge of HIV serostatus, injecting drug user survey 2005, Estonia

\begin{tabular}{lcc}
\hline & \multicolumn{2}{c}{ HIV + } \\
\hline $\begin{array}{l}\text { HIVare of serostatus } \\
\text { OR }(95 \% \text { CI })^{* *}\end{array}$ & $\begin{array}{c}\text { Unaware of serostatus } \\
\text { OR }(95 \% \text { CI })^{* *}\end{array}$ \\
\hline $\begin{array}{l}\text { Shark behaviour, last 4 weeks } \\
\text { Unprotected intercourse }\end{array}$ & $2.39(1.34-4.24)$ & $1.19(0.57-2.50)$ \\
(anal+vaginal) & $1.28(0.68-2.39)$ & $1.73(0.81-3.69)$ \\
$\begin{array}{l}\text { Sharing water } \\
\text { Risk behaviour, 12 months }\end{array}$ & $2.42(1.40-4.17)$ & $0.72(0.36-1.45)$ \\
$\begin{array}{l}\text { IDU as sex partner } \\
\text { Sharing injection equipment with }\end{array}$ & $2.42(1.31-4.47)$ & $0.64(0.32-1.27)$ \\
sexual partner & $4.47(2.36-8.46)$ & $0.95(0.39-2.31)$ \\
Having 2 or more sexual partners & $0.95(0.57-1.60)$ & $0.50(0.27-0.95)$ \\
Unprotected intercourse & $1.55(0.88-2.73)$ & $2.44(1.24-4.80)$ \\
Risk behaviour, lifetime & & \\
Sharing with HIV-positive person & $15.13(7.44-30.75)$ & $0.53(0.16-1.73)$ \\
\hline
\end{tabular}

* adjusted for site, gender, age, ethnicity, frequency of injection, jailed in the past, age at IDU initiation

** ref group is HIV-negatives 